\title{
CHEMICAL CONTRACEPTIVE TRIAL: II
}

\author{
ELEANOR MEARS \\ Council for the Investigation of Fertility Control, 64 Sloane Street, London, SW.1
}

(Received 16th May 1962)

\begin{abstract}
Summary. This trial was designed to compare the efficiency and acceptability of three different chemical contraceptive products a foaming tablet (Volpar foaming tablets), a pessary (Genexol pessaries), and a new aerosol foam cream (Emko foam), and it was conducted entirely by post. This was the second trial of its kind organized by the Council for the Investigation of Fertility Control. The foaming tablet used was the same as that used in the first trial. Since the result obtained for this preparation in both trials was similar, it was possible to compare the results of all five products used in both trials. It was found that the pregnancy rates for the aerosol foam cream were considerably lower than those for any other chemical contraceptive yet tested in this way. Since it calls for no medical supervision, this would appear to be an important finding. There was little difference in the overall acceptability of the three different products, though the reasons for liking or disliking were different in each case.

An improved system of follow-up was used in this trial, and as a result, information was available for $72 \%$ of the possible woman months as compared with only $39.7 \%$ in the previous trial.

The writer suggests that the efficiency of the aerosol foam cream (Emko foam) may well be similar to mechanical methods of contraception, and it is hoped that it may be possible to arrange a comparative trial of Emko foam and the two most commonly used mechanical methods, the condom and the diaphragm.
\end{abstract}

\section{INTRODUCTION}

The value of postal trials to compare the efficiency and acceptability of different chemical contraceptives was suggested when the results of the first three chemical trials by the Council for the Investigation of Fertility Control were published in a previous paper (Mears \& Please, 1962). Then, the number of patients dropping out made the results of doubtful validity; no significant difference was found between the efficiency or overall acceptability of the three contraceptives used, a cream (Emko foam), a foaming tablet (Volpar foaming tablets), and a pessary (Genexol pessaries). The advantages of a postal trial over the usual method of conducting trials, however, were undoubted, and it was decided to undertake a further trial with a more adequate system of followup in the hope of proving the value of such trials. 


\section{ORGANIZATION OF THE TRIAL}

As a result of newspaper publicity from all over the country, volunteer couples were sought who did not want a pregnancy, but were prepared to run a certain amount of risk. They were asked to give particulars of ages of both husband and wife, occupation of husband, number of years married, number of children, previous birth control methods, whether it had ever taken them long to achieve pregnancy. Volunteers were only accepted who had proved their fertility; those who seemed to be infertile (i.e. who had attempted pregnancy for 12 months without success) were not accepted. When accepted, volunteers were sent charts to record menstruation and times of coitus (to be marked with ' $\mathrm{X}$ ' when the method supplied was used, by ' $\mathrm{O}$ ' whenever unprotected intercourse took place). A 3-months supply of the first chemical contraceptive was sent and they were asked to return the chart at the end of the 3 months with their comments about the use of the product. As in previous trials (Mears \& Please, 1962), volunteers were allotted to one of the six possible treatment groups by random process. These treatment groups represent all the possible variations in order of use of the three products. Emko foam (D), Volpar foaming tablets (E) and Genexol pessaries (F).

The period interval was defined as the interval between two menstruations. Volunteers were instructed to use one preparation only during each period interval, and to use each preparation for three successive period intervals. Each volunteer used all three preparations in order according to the treatment group to which they were allotted.

To assess the acceptability of the product, the volunteer was asked to record on the back of her chart, at the end of each 3 months, whether she found the method satisfactory or whether she had any complaints (these were listed for her to tick - troublesome, messy, causing irritation, dislike of smell, failure to dissolve). To make comparison between these and other methods more possible, she was asked to record whether she found the method more satisfactory than any other used, and with the second and third preparation during the trial, whether she preferred the one she had just finished or the previous one.

When the record chart was returned after the first and second 3-months treatment, 3-months supply of the second or third product and another chart of a different colour were immediately posted, so that each volunteer who completed the trial used all three different chemical contraceptives, each for 3 months, i.e. a total of 9 months. A wall chart was prepared showing the progress of every patient so that any volunteer who defaulted received immediately a follow-up letter. One of the products used, E (foaming tablets), was also used in the previous trial (B) in the hope that if the results for this preparation were comparable with the results in the first trial then the result of all five products in the two trials could be compared.

Four hundred and twenty-five volunteers were enrolled and were allocated to treatment groups. Eighty-five of these were 'non-starters' who were not heard from again or who became pregnant before starting, and 337 volunteers started the trial.

A total number of 177 patients dropped out during the course of the trial for one reason or another. Some rejoined to use a different preparation, so that 
the number of completed woman months should be examined. Altogether the 337 starters were in the trial for 2180 woman months, compared with a possible 3033 woman months, so that full information is available for $72 \%$ of the possible woman months. To examine whether the numbers dropping out of the trial related to the preparation used, the month in which the volunteer withdrew and the number who started that month must be considered.

The number of volunteers dropping out, distributed according to group, was examined and no significant difference between any of the groups was found, and therefore no relation between dropping out and the group allotted to. The number of volunteers dropping out, distributed according to the product used, was also examined. Forty-eight dropped out when using Product D, seventy-three when using Product $\mathrm{E}$ and fifty-six when using Product F. These figures suggest that a significantly larger proportion dropped out when using Product $\mathrm{E}$ rather than when using either Products D or F. However, there was little difference between those using the latter two products.

TABLE 1

PREGNANGY RATE DURING PROTEGTED MONTHS

\begin{tabular}{l|c|c|c|c}
\hline \multicolumn{1}{c|}{ Product } & $\begin{array}{c}\text { Woman months } \\
\text { protected }\end{array}$ & No. pregnant & $\begin{array}{c}\text { Rate/100 } \\
\text { woman months }\end{array}$ & $\begin{array}{c}\text { Rate/100 } \\
\text { woman years }\end{array}$ \\
Emko foam (D) & 561 & 4 & $0 \cdot 71$ & $9 \cdot 7$ \\
Volpar foaming tablets (E) & 586 & 20 & 3.4 & 41 \\
Genexol pessaries (F) & 599 & 10 & 1.67 & 20 \\
\hline
\end{tabular}

TABLE 2

PREGNANGY RATE DURING MONTHS WITH ANY UNPROTECTED INTERCOURSE

\begin{tabular}{l|c|c|c|c}
\hline \multicolumn{1}{c|}{ Product } & $\begin{array}{c}\text { Woman months } \\
\text { unprotected }\end{array}$ & No. pregnant & $\begin{array}{c}\text { Rate/100 } \\
\text { woman months }\end{array}$ & $\begin{array}{c}\text { Rate/100 } \\
\text { woman years }\end{array}$ \\
\hline Emko foam (D) & 161 & 6 & $3 \cdot 7$ & $44 \cdot 4$ \\
Volpar foaming tablets (E) & 142 & 7 & $4 \cdot 9$ & $58 \cdot 8$ \\
Genexol pessaries (F) & 131 & 7 & $5 \cdot 3$ & $63 \cdot 6$ \\
\hline
\end{tabular}

\section{RESULTS}

\section{EFFICIENCY}

It seemed that effectiveness could best be assessed as a comparison between rates for the different contraceptives. Obviously the effectiveness will bear some relation to carelessness and motivation of the volunteers in that a distasteful or unacceptable method will probably result in a higher proportion of volunteers withdrawing from the survey. The arrangement into six groups involving different products in random order sought to equalize factors such as motivation and to give more reliable pregnancy results. When analysing the results, it was found that a considerable proportion of couples had occasional unprotected intercourse where they marked an ' $O$ ' on the chart and these months have, of course, been analysed separately. Table 1 shows pregnancy rates both for those woman months when the method was used all the time, and Table 2 for those months when any unprotected intercourse occurred. 
The pregnancy rate per 100 woman months is the ratio of the number of pregnancies to the total number of months of exposure multiplied by 100 . The rate per 100 woman years is also included as this is the pregnancy rate used by some other investigators (Pearl, 1932, 1939; Tietze, 1959). It will be seen that there is a significant difference in the pregnancy rates. Product $\mathrm{D}$ with a pregnancy rate of 0.71 per 100 woman months would appear to be markedly more efficient than the other products in the trial. Since the rate for Product $\mathrm{E}$ at 3.4 is almost exactly the same as the pregnancy rate for the same product in the previous trial (3.68 for the protected months, Mears \& Please, 1962), it is possible to compare the efficiency of all five products used in the two trials and the following table shows these results (Table 3).

TABLE 3

PREGNANCY RATE FOR PROTECTED MONTHS

\begin{tabular}{l|c|c|c}
\hline & $\begin{array}{c}\text { Woman months } \\
\text { protected }\end{array}$ & $\begin{array}{c}\text { Pregnancy ratel } \\
100 \text { woman months }\end{array}$ & $\begin{array}{c}\text { Pregnancy ratel } \\
100 \text { woman years }\end{array}$ \\
\hline First Trial & & 579 & $2 \cdot 42$ \\
A (cream) & 571 & $3 \cdot 75$ & 29 \\
B (foaming tablets) & 540 & $3 \cdot 18$ & 45 \\
G (pessaries) & & & 38 \\
\hline Second Trial & 561 & $0 \cdot 71$ & $9 \cdot 7$ \\
D (Emko foam) & $3 \cdot 4$ & 41 \\
F (Volpar foaming tablets) & 586 & $1 \cdot 67$ & 20 \\
Rendell's new pessaries) & 599 & & \\
\hline
\end{tabular}

TABLE 4

PREGNANCY RATES PER MONTH

\begin{tabular}{|c|c|c|c|c|c|c|}
\hline \multirow[b]{2}{*}{ Month } & \multicolumn{3}{|c|}{ Protected } & \multicolumn{3}{|c|}{ Unprotected } \\
\hline & $\begin{array}{l}\text { Woman months } \\
\text { protected }\end{array}$ & No. pregnancies & $\%$ & $\begin{array}{c}\text { Woman months } \\
\text { unprotected }\end{array}$ & No. pregnancies & $\%$ \\
\hline $\begin{array}{l}1 \\
2 \\
3 \\
4 \\
5 \\
6 \\
7 \\
8 \\
9\end{array}$ & $\begin{array}{l}254 \\
262 \\
247 \\
199 \\
193 \\
173 \\
145 \\
133 \\
140\end{array}$ & $\begin{array}{l}9 \\
4 \\
4 \\
4 \\
6 \\
4 \\
2 \\
0 \\
1\end{array}$ & $\begin{array}{l}3 \cdot 5 \\
1 \cdot 5 \\
2 \\
2 \\
3 \\
2 \\
1 \\
0 \\
1\end{array}$ & $\begin{array}{l}83 \\
71 \\
66 \\
40 \\
36 \\
43 \\
35 \\
38 \\
22\end{array}$ & $\begin{array}{l}0 \\
6 \\
7 \\
2 \\
1 \\
1 \\
1 \\
1 \\
1\end{array}$ & $\begin{array}{r}0 \\
8 \\
11 \\
5 \\
3 \\
2 \\
3 \\
3 \\
5\end{array}$ \\
\hline Total & 1746 & 34 & 2 & 434 & 20 & 5 \\
\hline
\end{tabular}

The Emko foam (D) is by far the most efficient of these five products. The Genexol pessaries (F) used in the second trial also have a lower pregnancy rate and would seem to be more efficient than the other products, while Cream A in the first trial comes midway between these and the ones with the lowest efficiency, Volpar foaming tablets and Rendeli's pessaries.

Looking at the pregnancy rates per month (Table 4), it will be seen that the biggest number of pregnancies occurs in the 1st month and that the numbers are 
greater for the first 6 months and fewer towards the end of the trial. The number pregnant among the unprotected group fluctuates more widely, and in every group the pregnancy rate for the unprotected is markedly higher than for the protected. It is interesting to conjecture why the number of pregnancies should be greater in the early months. Is it that the more fertile couples become pregnant then and that the chances of pregnancy are therefore less later? This accords with the views of Tietze, Guttmacher \& Rubin (1950).

\section{ACGEPTABILITY}

Table 5 shows the acceptability for the three products. Volunteers were all asked

TABLE 5

OPINIONS OF VOLUNTEERS

\begin{tabular}{|c|c|c|c|c|c|c|}
\hline \multirow[t]{2}{*}{ Product: } & \multicolumn{2}{|c|}{$\begin{array}{c}\text { Emko foam } \\
(D)\end{array}$} & \multicolumn{2}{|c|}{$\begin{array}{c}\text { Volpar foaming } \\
\text { tablets } \\
(E)\end{array}$} & \multicolumn{2}{|c|}{$\begin{array}{c}\text { Genexol } \\
\text { pessaries } \\
(F)\end{array}$} \\
\hline & No. & $\%$ & No. & $\%$ & No. & $\%$ \\
\hline $\begin{array}{l}\text { Acceptability } \\
\text { Objections } \\
\text { No answer } \\
\text { Preferred to } \\
\text { any other } \\
\text { method } \\
\text { Preferred to } \\
\text { others in the } \\
\text { trial }\end{array}$ & $\begin{array}{r}190 \\
92 \\
14 \\
155\end{array}$ & $\begin{array}{r}77 \\
37 \\
6\end{array}$ & $\begin{array}{r}176 \\
110 \\
26\end{array}$ & $\begin{array}{l}69 \\
43 \\
10\end{array}$ & $\begin{array}{r}220 \\
64 \\
25\end{array}$ & $\begin{array}{l}87 \\
25 \\
10\end{array}$ \\
\hline
\end{tabular}

whether they were satisfied with the product, if they had any objections, whether they preferred it to any other method and whether they preferred it to the others in the trial. It will be seen that there is a slight preference all through for Product F (Genexol pessaries) in that it has the highest degree of acceptability, the smallest percentage of objections, the largest number of subjects who prefer this to any other method, a slightly larger number who prefer it to others in the trial, and the fewest months of unprotected intercourse. There is little difference, however, between Product $\mathrm{E}$ and Product $\mathrm{F}$ overall, as in fact fewer patients drop out using Product D than either of the others. Product E, the foaming tablets, were the least acceptable all round, found most objections and fewest preferences. Table 6 shows the actual complaints mentioned by the volunteers. The cream, which has to be applied with an applicator, is found to be more troublesome than either foaming tablets or gels which are simply inserted with the fingers. The most common complaint is of messiness, and this is made slightly more often with the Emko, though this is probably not significant. Forty-two per cent of subjects using foaming tablets complain of irritation. Comparing these complaints with those mentioned in the previous trial, it will be seen that the actual complaints seem to be related to the kind of product - that is whether cream, gel or foaming tablet, rather than to the particular product.

In both trials, the cream with applicator has been most troublesome, the 
foaming tablets produced most irritation, etc. Emko would appear to be remarkably bland with only $6 \%$ of volunteers complaining of irritation.

It is important to note that volunteers did not always drop out when they made complaints.

TABLE 6

COMPLAINTS OF VOLUNTEERS

\begin{tabular}{|c|c|c|c|c|c|c|c|c|c|c|}
\hline \multirow{2}{*}{ Product } & \multicolumn{2}{|c|}{ Troublesome } & \multicolumn{2}{|c|}{ Messy } & \multicolumn{2}{|c|}{ Irritating } & \multicolumn{2}{|c|}{$\begin{array}{l}\text { Dislike } \\
\text { smell }\end{array}$} & \multicolumn{2}{|c|}{$\begin{array}{l}\text { Failure to } \\
\text { dissolve }\end{array}$} \\
\hline & No. & $\%$ & No. & $\%$ & No. & $\%$ & No. & $\%$ & No. & $\%$ \\
\hline $\begin{array}{l}\text { Emko foam } \\
\text { (D) } \\
247 \text { opinions }\end{array}$ & 71 & $28 \cdot 8$ & 86 & $34 \cdot 8$ & 15 & 6 & 7 & $2 \cdot 8$ & - & - \\
\hline $\begin{array}{l}\text { Volpar } \\
\quad \text { foaming } \\
\text { tablets }(E) \\
257 \text { opinions }\end{array}$ & 18 & 7 & 67 & 26 & 109 & 42 & 10 & $3 \cdot 9$ & 13 & 5 \\
\hline $\begin{array}{l}\text { Genexol } \\
\text { pessaries } \\
(\mathbf{F}) \\
252 \text { opinions }\end{array}$ & 12 & $4 \cdot 8$ & 60 & $23 \cdot 8$ & 57 & 23 & 10 & 4 & 1 & $0 \cdot 4$ \\
\hline
\end{tabular}

\section{DISCUSSION}

This is an account of the second postal trial designed to compare the efficiency and acceptability of three different chemical contraceptives - a new aerosol foam, a foaming tablet and a pessary - and to question again the value of postal trials.

Three hundred and thirty-seven women took part in the trial for 2180 compared with the possible 3033 woman months. Thus information was only available for $72 \%$ of the possible woman months. As full information was only available for $39.7 \%$ of the possible woman months in the previous three-product trial, the system of follow-up which has been used this time would appear to be satisfactory and to prove the value of postal trials where there is an adequate follow-up.

The new Emko aerosol foam has been shown to be much more efficient than any other product used in either trial. This is the first time that there has been any significant difference in the efficiency of any one chemical contraceptive used in trials under the auspices of the Council for the Investigation of Fertility Control in this country. Since this is a method that calls for no medical supervision, this would appear to be an important finding. The efficiency of Emko foam is similar to that reported by Paniagua, Predras, Vaillant \& Gamble (1961), who point out that this contraceptive foam does not deteriorate in the hot climate which prevails in most areas where population increase is sharpest. As was said in a Lancet leader (18th November 1961): 'the efficacy of the foam is far less than that of the pill, but demographically its efficacy cannot be ignored; and the simplicity of this method, which involves very little instruction and no medical follow-up, justifies extended trials, possibly with norethynodrel 
as an alternative for those who are capable of using it intelligently and who experience side-effects'.

The writer suggests that the efficiency of this method may well be similar to mechanical methods of contraception, and it is hoped that it might be possible to arrange a comparative trial of Emko foam and the two most commonly used mechanical methods, the condom and the diaphragm.

The acceptability of the products has also been considered. The overall acceptability of the Genexol pessaries (F) and the Emko vaginal foam (D) is very similar, both of them much better than foaming tablets, which produce a marked degree of irritation (in $42 \%$ of volunteers). The actual complaints made by volunteers in both trials seem to be related to the kind of product; thus creams with applicators are by far the most troublesome; foaming tablets and gels, which are inserted with fingers, are markedly less so. Foaming tablets are much more irritating than the other methods. However, volunteers did not always drop out when they made complaints. The overall acceptability of the product, bearing in mind all the objections and complaints, is not very variable and not markedly different, though the objections mentioned do vary from one product to another.

\section{REFERENCES}

Mears, E. \& Please, N. (1962) Chemical contraceptive trial. J. Reprod. Fertil. 3, 138.

Paniagua, M. E., Predras, R., Vaillant, H. W. \& Gamble, C. J. (1961) Field trial of a contraceptive foam in Puerto Rico. 7. Amer. med. Ass. 177, 125.

Pearl, R. (1932) Contraception and fertility in 2000 women. Hum. Biol. 4, 363.

PEarL, R. (1939) The natural history of population. Oxford University Press, New York.

Tietze G. (1959) The clinical effectiveness of contraceptive methods. Amer. 7. Obstet. Gynec. 78, 650.

Tietze, G., Gutrmacher, A. F. \& Rubin, S. (1950) Time required for conception in 1727 planned pregnancies. Fertil. Steril. 1, 338. 